\title{
Comparison between extraction methods of photosynthetic pigments in Acacia mangium
}

\author{
Susana Cristine Siebeneichler, Jacqueline Silva Barbosa, Antônio Marcos Milhomem Cruz, Marilene Alves \\ Dias Ramos, Hallefy Elias Fernandes and Vitor L. Nascimento*
}

Universidade Federal do Tocantins, Gurupi, TO, Brazil

*Author for correspondence: vitorlnasc@gmail.com

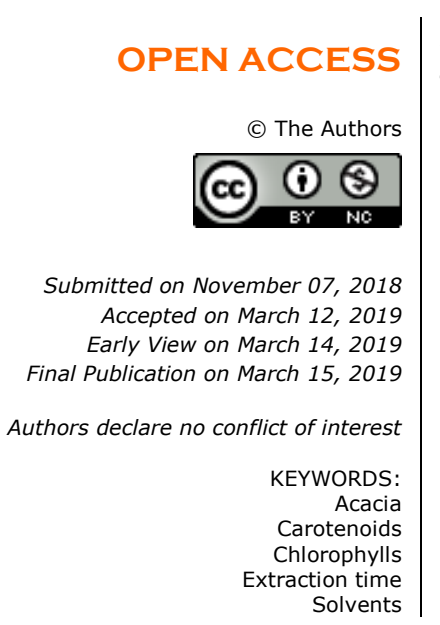

\section{ABSTRACT}

The aim of this work was to determine a simple and rapid protocol for the extraction of photosynthetic pigments (chlorophylls and carotenoids) from Acacia mangium (Willd.), a pioneer species with rapid growth and that has been used in commercial forests in northern Brazil. The experiment consisted of $4 \times 5$ factorial, 4 solvents (ethanol, dimethylsulfoxide (DMSO), N,N-dimethylformamide (DMF), and $80 \%$ acetone) and 5 extraction times $(24,48$, 72,96 , and 120 hours). The equations used for calculations varied according to the solvent used. For a quantification of the photosynthetic pigment contents of $A$. mangium it is recommended to use $80 \%$ acetone with 84 hours of extraction since this solvent allows the efficient extraction of both chlorophylls and carotenoids with a single protocol.

\section{Highlighted Conclusion}

Determination of the Acacia leaves pigments (chlorophylls and carotenoids) it is possible with a single protocol in 84 hours, using an extraction with $80 \%$ acetone.

\section{INTRODUCTION}

Acacia (Acacia mangium Willd. - Fabaceae) is a native species from northwestern Australia, Papua New Guinea and western Indonesia, which was introduced in Brazil about 30 years ago, leading to interest by its rusticity, rapidity of growth and being a nitrogen-fixing species (Smiderle et al. 2005, Aguiar Jr et al. 2013, Attias et al. 2014).

The analysis of foliar pigments is an useful tool for the study of plant responses to the environment and for the elaboration of management practices, aiming to increase the photosynthetic potential and plants yield (Pompelli et al. 2013, Daniel et al. 2016). These pigments can be divided into those that act actively in light capture in the photochemical phase, the chlorophylls, and those that act as accessory pigments in the dispersion of excess light energy, such as carotenoids (Streit et al. 2005, Cruz et al. 2007, Jesus and Marenco 2008).

Chlorophylls and carotenoids contents can be obtained by extraction with organic solvents (Silva et al. 2014) and there are several methodologies already elucidated for the extraction of these pigments in diverse vegetal species, as the use of ethanol (Wintermans and De Mots 1965, Lichtenthaler 1987), N,N-dimethylformamide (DMF) (Moran 1982, Wellburn 1994), 80\% acetone and dimethylsulfoxide (DMSO) (Barnes et al. 1992, Wellburn 1994). However, there are considerable variations in the extraction of pigments, depending on the methodology used being that the main sources of variation include: (i) nature, polarity and purity degree of the solvent; (ii) temperature and incubation/extraction time; and (iii) the equations used, which must be specific to the different solvents (Porra et al. 1989, Tait and Hik 2003, Ritchie 2008, Barbieri Junior et al. 2010). In addition, the species is an important source of variation regarding the extraction methodology of photosynthetic pigments, since the contents of these compounds diversifies according to the organisms.

The aim of this work was to determine the best protocol for extraction of $A$. mangium foliar pigments considering four solvents and five extraction times.

\section{MATERIAL AND METHODS}

The present work was developed in the Universidade Federal do Tocantins (UFT) - Campus Gurupi. Completely expanded leaves were collected from the apex of plants, approximately one meter high, located in full sunlight, in 
the seedling nursery of the campus. The randomly collected leaves were stored in plastic bags and immediately taken to the laboratory for the start of the analysis.

The experimental design was completely randomized in a $4 \times 5$ factorial scheme, with 3 replicates, totaling 60 samples. The first factor consisted of four solvents types (ethanol, DMSO, DMF, and $80 \%$ acetone), and the second, five extraction times (24, 48, 72, 96, and 120 hours).

The samples were composed of $100 \mathrm{mg}$ of chopped leaves, eliminating the thicker veins, and weighed in an analytical balance. Then, these samples were transferred to tubes previously coated to avoid degradation of chlorophylls by contact with light. In the tubes were added $5 \mathrm{~mL}$ of the respective extractors. The pigment quantification was performed by spectrophotometry, with wavelengths of $665 \mathrm{~nm}$ and $646 \mathrm{~nm}$ for chlorophylls, and $470 \mathrm{~nm}$ for carotenoids. After each incubation time, at room temperature, the absorbance readings were performed in a digital spectrophotometer (Edutec EEQ 9023), for this, part of the solution was transferred to $3 \mathrm{~mL}$ glass cuvettes.

The methodologies and equations used were: (i) for ethanol according to Lichtenthaler (1987), Pompelli et al. (2013) and Sumanta et al. (2014); (ii) for DMSO according to Barnes et al. (1992) and Wellburn (1994); (iii) for DMF according to Moran (1982) and Wellburn (1994); and (iv) to 80\% acetone, following Barnes et al. (1992) and Wellburn (1994). The equations are presented below:

(i) ethanol:

Chl a $=13.36 * A_{665}-5.19 * A_{646}$

Chl $\mathrm{b}=27.43 * A_{646}-8.12 * 665$

Chl total $=5.24 * A_{665}+22.24 * A_{646}$

Car $=\frac{1000 * A_{470}-2.13 * \text { Chl a }-97.64 * \text { Chl b }}{209}$

(ii) DMSO:

Chl a $=14.85 * A_{665}-5.14 * A_{646}$

Chl $\mathrm{b}=25.48 * A_{646}-7.36 * A_{665}$

Chl total $=7.49 * A_{665}+20,34 * A_{646}$

$C a r=\frac{1000 * A_{470}-2.14 * C h l \mathrm{a}-70.16 * C h l \mathrm{~b}}{220}$

(iii) DMF

Chl a $=12.64 * A_{665}-2.99 * A_{646}$

Chl $\mathrm{b}=23.26 * A_{646}-5.6 * A_{665}$

Chl total $=7.04 * A_{665}+20.27 * A_{646}$

Car $=\frac{1000 * A_{470}-0.89 * \text { Chl a }-52.02 * \text { Chl b }}{245}$

(iv) $80 \%$ acetone:

Chl a $=12.58 * A_{665}-2.93 * A_{646}$

Chl b $=21.14 * A_{646}-5.09 * A_{665}$

Chl total $=7.49 * A_{665}+18.21 * A_{646}$

Car $=\frac{1000 * A_{470}-3.27 * \text { Chl a }-104 * \text { Chl b }}{198}$

wherein: $\mathrm{Chl} \mathrm{a}=$ chlorophyll $\mathrm{a}, \mathrm{Ch} / \mathrm{b}=$ chlorophyll $b, \mathrm{Ch} /$ total $=$ total chlorophylls, $\mathrm{Car}=$ carotenoids, and 665,646 and $470=$ wavelengths $(\mathrm{nm})$ used.

The analyzed variables were: chlorophylls $a, b$ and total, chlorophyll $a / b$ ratio, and carotenoids. Defined the best solvent, by means of derived from the equations, the maximum extraction points were defined for each

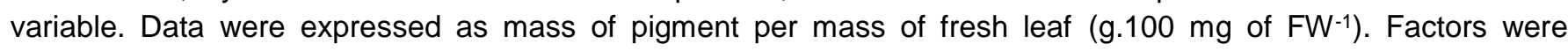
analyzed by regressions according to models available in the software SigmaPlot 10.0 .

\section{RESULTS AND DISCUSSION}

Chlorophyll content ranged from 4.5 to $18.0 \mathrm{~g} .100 \mathrm{mg}$ of FW-1, to chlorophyll a, from 0.4 to $5.5 \mathrm{~g} .100 \mathrm{mg}^{-1}$ of FW- to chlorophyll $b$, and from 5.0 to $22.5 \mathrm{~g} .100 \mathrm{mg}$ of $\mathrm{FW}^{-1}$, to total chlorophylls (Figures $1 \mathrm{~A}, 1 \mathrm{~B}$, and $1 \mathrm{C}$ ). The model that best fits the variables is the polynomial, presenting coefficients of determination between 0.17 and $0.97,0.83$ and 
$0.99,0.31$ and 0.98 , respectively for chlorophylls $a, b$, and total. For the chlorophyll $a / b$ ratio, the model that best fits the data is the polynomial, presenting coefficients of determination between 0.78 and 0.97 (Figure 1D).
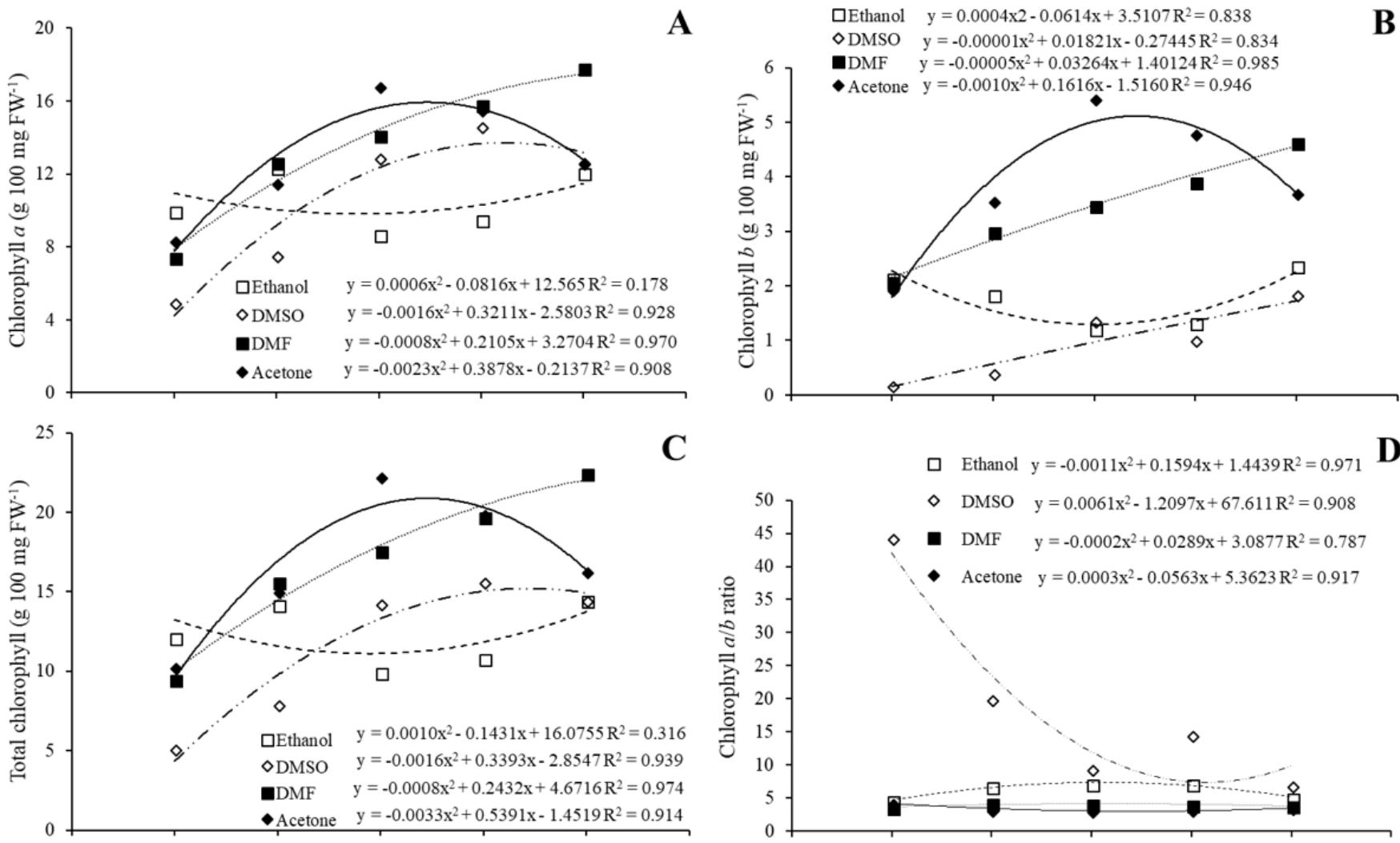

$\mathrm{C}$

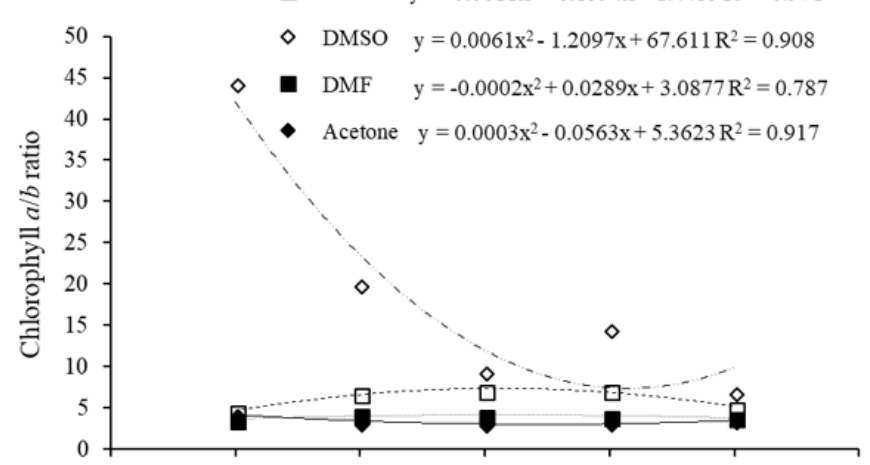

QEthanol $\mathrm{y}=0.0003 \times 2-0.0363 \mathrm{x}+3.6953 \mathrm{R}^{2}=0.822$
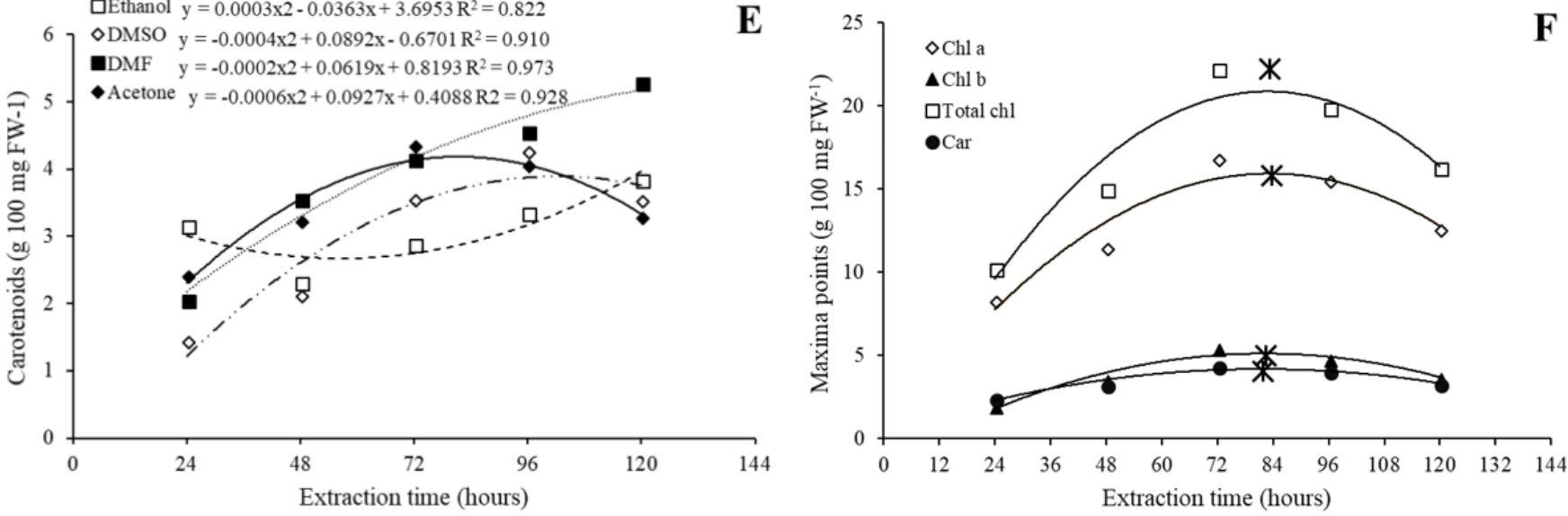

Figure 1. Acacia mangium (Willd.) content of chlorophylls a (A), b (B), total (C), chlorophyll a/b ratio (D), and carotenoids (E) in different solvents (ethanol, DMSO - dimethylsulfoxide, DMF - N,N-dimethylformamide, and $80 \%$ acetone) and extraction times (24, 48, 72, 96, and 120 hours), and the maxima extraction points of chlorophylls $a, b$, total, and carotenoids content with $80 \%$ acetone extraction $(F)$.

In relation to carotenoids, the data fit the polynomial model and presented coefficients between 0.822 and 0.973 . The contents ranged from 1.4 to $5.3 \mathrm{~g} .100 \mathrm{mg}$ of FW-1 (Figure 1E) The extraction pattern of this accessory pigment in the solvents used presented basically the same responses for the chlorophyll content.

Unlike what happened in the extraction of chlorophylls (Figures 1A, 1B, and 1C), the DMF was able to extract a greater level of carotenoids than $80 \%$ acetone, in less incubation time of the samples. While it took time over 96 hours of DMF extraction to obtain higher amounts of chlorophyll, for carotenoids after 72 hours the use of DMF becomes more efficient than $80 \%$ acetone (Figure 1E). Ethanol and DMSO were not efficient for the extraction of carotenoids from $A$. mangium (Figure 1E).

An increase in chlorophyll concentration over time is observed, except for ethanol. However, after 96 hours of incubation, a decrease in chlorophyll $a$ and total contents occurred with $80 \%$ acetone and DMSO. There is also a decrease in chlorophyll $b$ extracted with $80 \%$ acetone and this decrease is due to the prolonged exposure time of 
the leaves to these solvents, promoting the pigments degradation. It is worth mentioning that when using DMF, no decrease of pigments was observed, which means that the degradation of chlorophyll molecules by this solvent will occur after 120 hours of incubation. It is also interesting to note the response presented by ethanol, which had a different response from the others, both for chlorophyll $a$ and $b$, and consequently total chlorophyll, wherein the extraction with this solvent shows a drop and subsequently an increase (Figure 1).

Barbieri Junior et al. (2010) aimed at defining the best chlorophyll extraction protocol in Tifton 85 grass leaves considering different solvents and extraction times, and they find minor variation in the concentrations extracted over time, regardless of the pigment and the solvent used. These results differ from those found in this work, where a great variation over time, depending on the pigment and solvent used, demonstrating how distinct species present different behaviors regarding pigment extraction methodologies.

In general, the solvent that recovered the largest amount of chlorophyll $a$ and total was DMF. However, the contents with this solvent were higher than those extracted with $80 \%$ acetone only after 96 hours. In addition, for chlorophyll $b$, the maximum contents extracted were with $80 \%$ acetone. The long time required for the DMF to extract higher concentrations of chlorophyll $a$ and total, makes it impracticable to use, because with the use of acetone the values found for these two variables are very close to those of DMF, and still in a shorter time extraction. The worst results found for extraction of chlorophyll $a$ and $b$ were ethanol and DMSO, respectively. Not being, therefore, recommended for the extraction of photosynthetic pigments of leaves of $A$. mangium (Figures $1 \mathrm{~A}$, $\mathrm{B}$ e C).

These results are opposite to those found by Cruz et al. (2007), in which for Bixa orellana L. hybrids the use of DMSO was recommended. In contrast, Barbieri Junior et al. (2010) obtained favorable results for $80 \%$ acetone for chlorophyll $b$, and lower recovery in DMSO, as well as those found in this study. The same authors point out the inefficiency of ethanol as an extractor of these pigments, and recommends DMF, DMSO, or $80 \%$ acetone for extraction of total chlorophyll of Tifton 85 grass. The different results found in distinct species, once again demonstrate the importance of determining a specific extraction protocol for each species, considering the time and solvent to be used.

It is observed that the chlorophyll $a / b$ ratio is very high in the first hours of DMSO extraction, evidencing previous results. Demonstrating the inefficiency of DMSO for the extraction of chlorophyll $b$ in shorter periods. The ratio obtained using ethanol showed insignificant variation as a function of time. In the same way, it occurred with the other solvents, being practically uniform, being, therefore, the most suitable for the extraction of the two types of chlorophylls (Figure 1D).

DMF is the most recommended solvent for the extraction of carotenoids. However, in the extraction of chlorophyll pigments, mainly of type $b$, where it excelled in relation to DMF, $80 \%$ acetone presented satisfactory results. Thus, to determine a fast and operational protocol for the extraction of photosynthetic pigments from leaves of $A$. mangium, the maximum extraction points of the pigments were established considering $80 \%$ acetone. There is a demand to reduce as much as possible the time of accomplishment of some activities, also reducing the costs of analysis. In this way, it is verified that approximately 84 hours after immersion in $80 \%$ acetone, it is the time in which the maximum recovery of pigments is obtained (Figure 1F), being the time and extractor recommended for the extraction and quantification of chlorophyll and carotenoid contents from leaf samples of $A$. mangium.

\section{References}

Aguiar Jr A et al. 2013. Invasion of Acacia mangium in Amazonian savannas following planting for forestry. Plant Ecology \& Diversity 7:359-369. Attias N et al. 2014. Acácias australianas no Brasil: histórico, formas de uso e potencial de invasão. Biodiversidade Brasileira 3:74-96.

Barbieri Junior E et al. 2010. Comparação de métodos diretos de extração e quantificação dos teores de clorofilas em folhas do capim-Tifton 85. Ciência Rural 40:633-636.

Barnes JD et al. 1992. A reappraisal of the use of DMSO for the extraction and determination of chlorophylls $a$ and $b$ in lichens and higher plants. Environmental and Experimental Botany 32:85-100.

Cruz ACF et al. 2007. Métodos Comparativos na Extração de Pigmentos Foliares de Três Híbridos de Bixa orellana L. Revista Brasileira de Biociências 5:777-779.

Daniel ES et al. 2016. Relação entre o teor absoluto e relativo de clorofila em folhas de vimeiro. Ciência Florestal 26:307-312.

Jesus SV, Marenco RA. 2008. O SPAD-502 como alternativa para a determinação dos teores de clorofila em espécies frutíferas. Acta Amazonica 38:815-818.

Lichtenthaler HK 1987. Chlorophylls and carotenoids: pigments of photosynthetic biomembranes. Methods in Enzymology 148:350-382.

Moran R 1982. Formulae for determination of chlorophyllous pigments extracted with N,N-dimethylformamide. Plant Physiology 69:1376-1381.

Pompelli MF et al. 2013. Spectrophotometric determinations of chloroplastidic pigments in acetone, ethanol and dimethylsulphoxide. Brazilian Journal of Biosciences, 11:52-58.

Porra RJ et al. 1989. Determination of accurate extinction coefficients and simultaneous equations for assaying chlorophylls $a$ and $b$ extracted with four different solvents: verification of the concentration of chlorophyll standards by atomic absorption spectroscopy. Biochimica et Biophysica Acta 975:384-394. 
Ritchie RJ 2008. Universal chlorophyll equations for estimating chlorophylls $a, b, c$, and $d$ and total chlorophylls in natural assemblages of photosynthetic organisms using acetone, methanol, or ethanol solvents. Photosynthetica 46:115-126.

Silva MA et al. 2014. Pigmentos fotossintéticos e índice SPAD como descritores de intensidade do estresse por deficiência hídrica em cana-deaçúcar. Bioscience Journal 30:173-181.

Smiderle OJ et al. 2005. Tratamentos pré-germinativos em sementes de Acácia. Revista Brasileira de Sementes 27:78-85.

Streit NM et al. 2005. As clorofilas. Ciência Rural 35:748-755

Sumanta $\mathrm{N}$ et al. 2014. Spectrophotometric analysis of chlorophylls and carotenoids from commonly grown fern species by using various extracting solvents. Research Journal of Chemical Sciences 4:63-69.

Tait MA, Hik DS 2003. Is dimethylsulfoxide a reliable solvent for extracting chlorophyll under field conditions? Photosynthesis Research 78:8791.

Wellburn AR 1994. The spectral determination of chlorophylls a and b, as well as total carotenoids, using various solvents with spectrophotometers of different resolution. Journal of Plant Physiology 144:307-313.

Wintermans JFGM, De Mots A 1965. Spectrophotometric characteristics of chlorophylls a and b and their phenophytins in ethanol. Biochimica et Biophysica Acta 109:448-453. 